\title{
ОСНОВЫ ПРАВОВОГО РЕГУЛИРОВАНИЯ ПОЛИТИКИ ЕВРОПЕЙСКОГО СОЮЗА В ОБЛАСТИ ФИНАНСОВЫХ УСЛУГ
}

\begin{abstract}
Аннотация. В статье рассматриваются правовые аспекты регулирования отношений в области финансовых услуг в ЕС. Раскрываются особенности реализаџии принципа свободного движения капитала в различных областях финансовых услуг.

Ключевые слова: Международное право, европейское право, европейское экономическое право, европейское финансовое право, Европейский Союз, европейская экономическая интеграция, финансовый рынок Европейского Союза, финансовые услуги в Европейском Союзе, внутренний рынок Европейского Союза, передвижение капиталов в Европейском Союзе
\end{abstract}

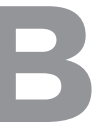

системе права Европейского Союза регулирование рынка финансовых услуг основано на реализации принципов внутреннего рынка ЕС - свободы движения капиталов, платежей и услуг, сформулированных в учредительных договорах Союза, без которых дальнейшее развитие финансового рынка данного интеграционного образования не представляется возможным. Формирование указанных экономических свобод оказало существенное воздействие на процесс свободного обращения на внутреннем рынке основных экономических факторов (продукция, капитал и рабочая сила). Это, по справедливому мнению Е.А. Дубовицкой , составляет «необходимое условие для оптимального распределения экономических ресурсов и, следовательно, для сбалансированного и постоянного развития экономики Сообщества»1․ Некоторые исследователи обоснованно добавляют к указанному перечню свободу движения платежей ${ }^{2}$. Аналогичной позиции придерживаются представители отечественной доктрины права ЕС, справедливо утверждая, что указанные свободы внутреннего рынка ЕC имеют особое значение для развития интеграционных процессов в Союзе ${ }^{3}$. Е.А.Чегринец рассматри-

\footnotetext{
${ }^{1}$ Дубовиикая Е.A. Европейское корпоративное право. 2-е изд., перераб. и доп. М., Волтерс Клувер, 2008. С. 1.

${ }^{2}$ Hafner, T. The Free Movement of Capital in the European Union. The Regulation of International Financial Markets: Perspectives for Reform. - Cambridge University Press, 2006. p. 143

${ }^{3}$ Право Европейского Союза в вопросах и ответах. Учебное пособие под ред. Кашкина С.Ю. М., Проспект, 2008. С. 43.
}

вает внутренний рынок в качестве основы, ядра, «вокруг которого развиваются и право Сообщества и само Сообщество. Центром же этого ядра, его смыслом являются четыре принципа, или четыре свободы внутреннего рынка» ${ }^{4}$.

\section{Свобода движения капитала}

Экономическая суть движения капитала определяется не переносом в другое государство акта реализации прибыли, заключенной в цене экспортируемых товаров, а сам процесс ее создания. Этот фактор, по словам О.С. Богданова, «предопределяет экономический интерес стороны, вывозящей капитал, что сочетается с заинтересованностью принимающей стороны в привлечении иностранного капитала и создания эффективного финансового рынка» ${ }^{5}$.

В Европейском Союзе полноценное функционирование финансового рынка и осуществление финансовых услуг стало возможным с появлением и реализацией свободы передвижения капитала, упомянутой впервые в пп. «с» п. 1 ст. 3 Договора об учреждении Европейского Сообщества. Согласно нормам указанной статьи деятельность Сообщества должна включать в себя «внутренний рынок, характеризуемый отменой препятствий

\footnotetext{
${ }^{4}$ Там же. С. 152.

${ }_{5}^{5}$ Международные экономические отношения. Учебник для вузов. Под. ред. проф. В.Е. Рыбалкина. 5-е изд., перераб. и доп. М., ЮНИТИ-ДАНА, 2005. С. 167.
} 
свободному передвижению товаров, лиц, услуг и капиталов между государствами-членами» ${ }^{6}$. При этом следует помнить, что нормам коммунитарного права, регулирующим указанные свободы, присущи следующие основные правовые принципы: принцип прямого действия, принцип отсутствия дискриминации и принцип верховенства права Европейского Союза'.

Как отмечается в российской правовой доктрине, под капиталом в праве Европейского Союза понимают «денежные средства (национальную и иностранную валюту), ценные бумаги и изделия из драгоценных металлов, принадлежащие гражданам государств-членов ЕС и юридическим лицам, зарегистрированным на территории государствчленов (резидентам)» ${ }^{8}$.

Толкование термина «передвижение капиталов» в широком смысле было дано Судом Европейских сообществ, в одном из решений которого было определено, что «передвижение капиталов» означает финансовые операции, существенно связанные с инвестированием соответствующих фондов ${ }^{9}$. Позднее толкование концепции «свободы передвижения капиталов» не раз являлось предметом решений, выносимых Судом $\mathrm{EC}^{10}$. Далее из практики Суда ЕС следует, что свобода передвижения капиталов является первоначальной свободой осуществления широкого круга финансовых операций: всех финансовых операций, связанных с инвестированием; инвестированием ресурсов в другое государство; невозвращение в страну своего первоначального местонахождения в разумный срок инвестированных финансовых ресурсов ${ }^{11}$.

${ }^{6}$ См. Договор об учреждении Европейского Сообщества, 1992. Право Европейского Союза: Документы и комментарии. Под ред. проф. Кашкина С.Ю. М., ТЕРРА, 1999. С.156.

${ }^{7}$ Case 237/82 Jongeneel Kaas BV v. Netherlands, (1984) ECR 483.

${ }^{8}$ Право Европейского Союза: правовое регулирование торгового оборота. Учебное пособие. Под ред. проф. В.В. Безбаха, доц. А.Я. Капустина, проф. В.К. Пучинского. - М., ЗЕРЦАЛО, 2000. С. 74.

${ }^{9}$ Case 286/82, 26/83 Luisi and Carbone v. Ministero del Tesoro (1984) ECR 377.

${ }^{10}$ Case C-367/98 Commission v Portugal; Case C-483/99 Commission v France; Case C-503/99 Commission v Belgium; Case C-463/00 Commission v Spain; Case C-98/01 Commission v United Kingdom; Case C-222/97 Trummer and Mayer.

${ }^{11}$ Case 7/78 R. v. Thompson (1978) ECR 2247; Case 194/84 Commission v. Greece (1987) ECR 4737;
Установив указанные ключевые характеристики понятия «движения капитала», можно признать, что Суд ЕС отождествил понятия «движение капитал» и «движение инвестиций», что нашло отражение в решении Суда ЕС по делу Konle ${ }^{12}$.

Как отмечается в юридической литературе, свобода передвижения капиталов длительное время в слабой степени являлась объектом внимания со стороны институтов Сообщества ${ }^{13}$. Первоначальная версия Договора об учреждении Европейского Экономического Сообщества не содержала формального обязательства обеспечить свободное движение капитала. Статья 67 данного Договора провозглашала только «обеспечение должного функционирования общего рынка в необходимых объемах» ${ }^{14}$. Дальнейшему развитию либерализации движения капитала способствовало принятие программы Европейской Комиссии по либерализации данной свободы общего рынка Сообщества в целях эффективной интеграции финансовых рынков и координации денежной и финансовой политики ${ }^{15}$. Данная программа включала три категории операций, связанных с прогрессивной либерализацией движения капитала: (i) операции с капиталом, опосредованные с другими свободами общего рынка; (ii) операции на рынке ценных бумаг и (iii) операции по кредитованию.

В связи с вступлением в силу с июля 1987 г. Единого европейского акта ${ }^{16}$, предусматривавшего по словам А.А. Ковалева «дальнейшее расширение международно-правовой базы экономической интеграции» ${ }^{17}$, и последующим переходом к единому рынку в 1993 г. нормы, регулировавшие свободу передвижения капиталов и платежей, зафиксированные в Договоре о Европейском Сообществе, были принципиально изменены

\footnotetext{
${ }^{12}$ Case C-302/97, Klaus Konle v. Austria (1997) ECR I-3099.

${ }^{13}$ См.: Основы права Европейского Союза. Под. ред. Кашкина С.Ю. М., Белые альвы , 1997. С. 201.

${ }^{14}$ Treaty establishing the European Economic Community (1957).

${ }^{15}$ Communication from the Commission to the Council of 23 May 1986 on the programme for the liberalisation of capital movements in the Community.COM(1986) 292 final.

${ }^{16}$ Single European Act // Official Journal of the European Communities. - 1987. - June 29.

${ }^{17}$ Ковалев А.А. Международное право и правовое регулирование международной экономической деятельности. Учебное пособие. М., Научная книга, 2007. С. 256.
} 
Маастрихтским договором (Договор о создании Европейского Союза), установившим отмену ограничений в свободном движении капитала и платежей между государствами-членами и между государствами-членами и третьими странами. Амстердамский договор, подписанный государствами-членами ЕС в 1997 г, не внес каких-либо существенных изменений в нормы, регулирующие свободу передвижения капиталов, сделав лишь редакционные правки.

Помимо положений, зафиксированных в ст. 3 Договора об учреждении Европейского Сообщества, нормы, регулировавшие свободу передвижения капиталов, подучили подробное закрепление в главе 4 указанного учредительного договора. Так, в п. 1 ст. 56 Договора об учреждении Европейского Сообщества установлено, что «в рамках положений, указанных в данной главе, все ограничения на передвижение капитала между государствами-членами и третьими странами должны быть запрещены» ${ }^{18}$. Существенным является тот факт, что Суд ЕС указал на прямое действие норм ст. 56 Договора об учреждении Европейского Сообщества ${ }^{19}$. Несмотря на тот факт, что Суд признал за этой статьей вертикальное прямое действие, он, по мнению Ашера, не утратил возможность признания за ней горизонтального прямого действия ${ }^{20}$.

Фундаментальные принципы свободы перемещения капитала, закрепленные в Договоре об учреждении Европейского Сообщества, получили дальнейшее развитие в нормах вторичного права. Как обоснованно указывает С.А. Бартенев, «основным законодательным инструментом, реализующим компетенцию ЕС в области свободы передвижения капитала, являются директивы» ${ }^{21}$.

Первой директивой, посвященной реализации принципа свободного перемещения капитала, является Директива о применении ст. 67 Договора об

${ }^{18}$ См.: Договор об учреждении Европейского Сообщества, 1992. Право Европейского Союза: Документы и комментарии. Под ред. проф. Кашкина С.Ю. - М.: ТЕРРА, 1999. С. 172.

${ }_{19}$ Cases 163/94, 165/94, 250/94 Criminal Proceedings against Lucas Emilio Sanz de Lera (1995) ECR I-4821 . Paras. 41-47.

${ }^{20}$ Usher, J. The Law of Money and Financial Services in the European Community. Oxford University Press. 1994. P. 27.

${ }^{21}$ Бартенев С.А. Европейский Союз и государства-члены: разграничение компетенции. М., Юрлитинформ, 2009. С. 139 учреждении $\mathrm{EЭC}^{22}$. Позднее указанная директива была дополнена Директивой 88/361 о применении ст. 67 Римского договора ${ }^{23}$. По обоснованному замечанию Е.А. Дубовицкой , Директива 88/361 положила начало процессу либерализации «в сфере движения капитала и платежного оборота», что в дальнейшем отразилось на редакции соответствующих норм Амстердамского договора ${ }^{24}$.

Директива 88/361, определявшая единый порядок движения капиталов в наличной и безналичной форме, установила, что государства-члены обязаны отменить все ограничения движения капиталов между резидентами соответствующих государств-членов с 1 июля 1990 г.

С целью облегчения применение норм Директивы 88/361 движение капиталов было ранжировано на 12 групп в соответствии с правилами, указанными в Приложении 1. Операции по купле-продаже акций, облигаций и других ценных бумаг, а также акций или долей участия (паев) в инвестиционных фондах были отнесены к третьей и четвертой группам. Нормы данной Директивы не касались права государств-членов принимать меры для предотвращения нарушений национального законодательства, в частности области налогообложения и валютного и финансового контроля, и устанавливать особую процедуру декларирования движения капиталов.

Дополнительно можно выделить ряд законодательных актов, обеспечивающих реализацию применения принципа свободы движения капитала в различных областях финансовых услуг. Среди них наиболее важными являются следующие. Директива 89/117 об обязательствах филиалов кредитных организаций и финансовых институтов ежегодно публиковать бухгалтерскую отчетность ${ }^{25}$, Директива 97/9 о схемах

\footnotetext{
${ }^{22}$ EEC Council: First Directive for the implementation of Article 67 of the Treaty. OJ 43, 12.7.1960, p. 921-932

${ }^{23}$ Council Directive 88/361/EEC of 24 June 1988 for the implementation of Article 67 of the Treaty. OJ L 178, 8.7.1988, p. 5-18.

${ }^{24}$ Дубовицкая Е.А. Указ. соч. С. 11.

${ }^{25}$ Council Directive 89/117/EEC of 13 February 1989 on the obligations of branches established in a Member State of credit institutions and financial institutions having their head offices outside that Member State regarding the publication of annual accounting documents (OJ L 44, 16.2.1989, p. 40-42).
} 
компенсации для инвесторов ${ }^{26}$, Директива 98/26 об установлении системы платежей и ценных бумаг ${ }^{27}$, Регламент 2157/2001 о статуте для европейской компании ${ }^{28}$, Директива о вспомогательных финансовых мерах ${ }^{29}$, Директива об оплате услуг на внутреннем рынке ${ }^{30}$.

С вступлением в силу Лиссабонского договора с 1 декабря 2009 г., дополняющего два учредительных договора: Договор о Европейском Союзе и Договор о создании Европейского Сообщества (далее - Лиссабонский договор) ${ }^{31}$ правовое регулирование отношений в финансовом секторе получило новый этап развития. Как пишет С.А. Бартенев, теперь Европейский Союз продолжит поступательное развитие, направленное на объединение уже 27 государств-членов» ${ }^{32}$ на усовершенствованной правовой основе: Договор о Европейском Союзе и Договор о функционировании Европейского Союза.

В Договоре о функционировании Европейского Союза большинство норм, регулирующих отношения в области финансовых услуг, были дополнены по сравнению с редакцией Договора об учреждении Европейского Сообщества ${ }^{33}$.

Так, полномочия в области внутреннего рынка, закрепленные в ст. 4 Договора о функционирова-

${ }^{26}$ Directive 97/9/EC of the European Parliament and of the Council of 3 March 1997 on investor-compensation schemes (OJ L 84, 26.3.1997, p. 22-31).

${ }^{27}$ Directive 98/26/EC of the European Parliament and of the Council of 19 May 1998 on settlement finality in payment and securities settlement systems (OJ L 166, 11.6.1998, p. 45-50).

${ }^{28}$ Council Regulation (EC) No 2157/2001 of 8 October 2001 on the Statute for a European company (SE) (OJ L 294, 10.11.2001, p. 1-21).

${ }^{29}$ Directive 2002/47/EC of the European Parliament and of the Council of 6 June 2002 on financial collateral arrangements (OJ L 168, 27.6.2002, p. 43-50).

${ }^{30}$ Directive 2007/64/EC of the European Parliament and of the Council of 13 November 2007 on payment services in the internal market amending Directives 97/7/EC, 2002/65/EC, 2005/60/EC and 2006/48/EC and repealing Directive 97/5/EC (OJ L 319, 5.12.2007, p. 1-36).

${ }^{31}$ Treaty of Lisbon amending the Treaty on European Union and the Treaty establishing the European Community. OJ 2007/C 306/01. 17.12. 2007.

${ }^{32}$ Бартенев С.А. Указ. соч. С. 116.

${ }^{33}$ Consolidated versions of the Treaty on European Union and the Treaty on the Functioning of the European Union. 2010/C 83/01. 30 March 2010 нии Европейского Союза, по-прежнему находятся в совместном ведении Союза и государств-членов. При этом под внутренним рынком понимается «пространство без внутренних границ, в рамках которого обеспечивается свободное движение товаров, лиц, услуг и капитала в соответствии с нормами учредительных договоров $\mathrm{EC} »^{34}$. Европейский Союз принимает на себя обязательство принять меры, направленные на установление или обеспечение функционирования внутреннего рынка. Следовательно, закрепление подобных обязательств Союза в учредительном договоре создает возможность использования свободы движения капитала, являющегося фундаментальным элементом организации внутреннего рынка EC, в качестве юридической платформы для дальнейшего регулирования финансовых услуг нормами вторичного права Европейского Союза.

Более подробно нормы, устанавливающие механизм свободы движения капитала, закреплены в ст.ст. 63-66 Договора о функционировании Европейского Союза, нормы которых предоставляют полную свободу передвижениям капитала, которые подвержены некоторым ограничениям в силу двух аспектов: внутреннего (реализация данной свободы между государствами-членами EC) и внешнего (передвижение капитала между государствами-членами и третьими странами) ${ }^{35}$. Данные ограничения состоят из трех групп.

В первую очередь ст. 65 Договора о функционировании Европейского Союза предоставляет государствам-членам право применять соответствующие положения национального налогового права, различающие налогоплательщиков по их месту регистрации или месту инвестирования капитала ${ }^{36}$. Реализация этой нормы может создать ситуацию, при которой государства-члены ЕС смогут принимать новое законодательство в области налогообложения, ограничивающее за счет такого различия передвижение капитала граждан, осуществляющих инвестиции в другое государство, и наоборот. Далее в этой же статье содержатся нормы, предоставляющие государствам-членам право (i) применять меры для предотвращения

\footnotetext{
${ }^{34}$ Ibid, Clause 26.2, p. 59

35 Право Европейского Союза. Учебник для вузов. Под ред. С.Ю. Кашкина. 3-е изд., перераб. и доп. М., Юрайт, 2010. С. 506

${ }^{36}$ Ibid. Clause 65.1 (a). p. 72
} 
нарушений национального законодательства в области налогообложения и осуществления пруденциального надзора за финансовыми учреждениями; (ii) устанавливать процедуры, требующие декларирования передвижения капитала в целях сбора административной или статистической информации; либо (iii) применять меры, оправданные целями поддержания общественной политики или общественной безопасности ${ }^{37}$.

Положения о второй группе ограничений закреплены в ст. 66 Договора о функционировании Европейского Союза, нормы которой позволяют Совету ЕС по предложению Европейской Комиссии и после консультаций с Европейским центральным банком в исключительных случаях принимать защитные меры в отношении третьих стран на срок, не превышающий 6 месяцев, если передвижение капитала в или из третьих стран вызывают или создают угрозу возникновения серьезных трудностей для функционирования экономического и валютного союза ${ }^{38}$.

Третья группа ограничений передвижения капитала между государствами-членами и третьими странами связана с ограничениями, возникшими по политическим причинам. Основаниями возникновения таких ограничений могут являться события в области общей внешней политики. В данном случае установление ограничений проводится с использованием процедур, установленных в ст. 215 Договора о функционировании Европейского Союза ${ }^{39}$.

В дополнение к указанным ограничениям С.Ю. Кашкин выделяет ограничение «status quo», установленное в ст. 57 Договора об учреждении Европейского Сообщества и препятствующее передвижению капитала с третьими странами, введенное государствами-членами или Сообществом до 31 декабря 1993 г. и действующее до настоящего момента ${ }^{40}$. Данные ограничения могут затрагивать следующие основные направления финансового рынка: (i) прямые инвестиции в предприятия; (ii) вложения в недвижимость; (iii) предоставление финансовых услуг и (iv) допуск ценных бумаг на финансовый рынок. Как отмечает С.Ю. Кашкин ,

\footnotetext{
${ }^{37}$ Ibid. Clause 65.1 (b). p. 72

${ }^{38}$ Ibid. Clause 66. p. 73

${ }^{39}$ Ibid. Clause 215. p. 144.

${ }^{40}$ Право Европейского Союза. Учебник для вузов. Под ред. С.Ю. Кашкина. 3-е изд., перераб. и доп. М., Юрайт, 2010. С. 507.
}

в отношении России указанные ограничения, за исключением прямых инвестиций, применяются в полной мере $\mathrm{e}^{41}$. В связи с прекращением срока действия Соглашения о партнерстве и сотрудничестве между ЕС и Россией 1994 г. и отсутствия нового соглашения вопрос в отмене ограничения данной категории применительно к свободному движению капитала между ЕС и Россией остается открытым.

Из вышеизложенного можно сделать вывод, что свобода движения капитала с полным основанием считается основой экономики и развития единого рынка Европейского Союза, а также юридической платформой для создания финансового рынка ЕС - задачи более сложной, чем простая элиминация торговых барьеров. Ведь по сравнению с тремя другими фундаментальными свободами общего рынка ЕС (передвижения лиц, товаров и услуг) финансовая свобода всегда была самой трудной, так как базировалась на национальном регулировании и поэтому была менее всего подвержена регулированию законодательными актами ЕС. В связи с этим закрепление в тексте последнего принятого в Союзе учредительного договора норм, направленных на становление и развитие финансового рынка является прямым подтверждением его значимости для интеграционного объединения.

\section{Свобода движения платежей}

Свобода движения капитала имеет неразрывную связь со свободой движения платежей, нормы о регулировании которых были зафиксированы в одной главе Договора об учреждении Европейского Сообщества, а в настоящее время продублированы в Договоре о функционировании Европейского Союза. Отдельные нормы, применяемые к свободе движения капитала, распространяются на свободу движения платежей.

Несмотря на схожие моменты, это две разных свободы внутреннего рынка ЕС, являющихся фундаментом правового регулирования политики в области финансовых услуг. Этот тезис подтверждается упомянутым решением Суда ЕС по делу Luisi and Carbone, в котором было осуществлено разграничение операций по передвижению капитала и платежей, определяя последние как

\footnotetext{
${ }^{41}$ Там же.
} 
«перечисления в иностранной валюте, предоставляющие вознаграждение в контексте лежащей в основе сделки» ${ }^{42}$. Аналогичное определение было дано Судом ЕС по делу Ministere Public ${ }^{43}$.

До вступления в силу Лиссабонского договора свобода движения капиталов регулировалась положениями ст. 56-60 Договора об учреждении Европейского Сообщества. В п. 2 ст. 56 Договора об учреждении Европейского Сообщества установлен режим полной либерализации платежей между государствами-членами, государствами-членами и третьими странами, т.е. все ограничения на свободу движения платежей между государствами-членами ЕС устранены. Применительно к платежам между государствами-членами ЕС и третьими странами ст. 60 Договора об учреждении Европейского Сообщества устанавливала только одно ограничение, связанное с возможностью ограничивать платежи в рамках мер, принимаемых в ходе ведения внешней политики Сообщества (ст. 301).

В настоящий момент нормы о регулировании свободы движения платежей установлены в ст. 63-66 Договора о функционировании Европейского Союза ${ }^{44}$ и источниках вторичного права. По своему содержанию и смыслу нормы Договора о функционировании Европейского Союза аналогичны анализированным выше нормам, содержащимся в Договоре об учреждении Европейского Сообщества. Примерами законодательных актов ЕС в сфере текущих платежей могут являться Регламент о трансграничных платежах в евро, определяющий три категории платежей (трансграничные кредитные переводы, трансграничные электронные платежи, трансграничные чеки $)^{45}$, и Директива о трансграничных кредитных переводах ${ }^{46}$.

${ }^{42}$ Case 286/82, 26/83 Luisi and Carbone v. Ministero del Tesoro (1984) ECR 377.

${ }^{43}$ Case 308/86, Ministere Public v. Lambert (1988) ECR 4369.

${ }^{44}$ Consolidated versions of the Treaty on European Union and the Treaty on the Functioning of the European Union. 2010/C 83/01. 30 March 2010.

${ }^{45}$ Regulation (EC) No 2560/2001 of the European Parliament and of the Council of 19 December 2001 on cross-border payments in euro. OJ L 344, 28.12.2001, p. 13-16.

${ }^{46}$ Directive 97/5/EC of the European Parliament and of the Council of 27 January 1997 on cross-border credit transfers. OJ L 43, 14.2.1997, p. 25-30.
Таким образом, свобода движения платежей характеризуется следующими чертами: (i) отсутствуют ограничения на свободу движения платежей между государствами-членами ЕC; (ii) платежи перечисляются в иностранной валюте (т.е. валюте государства-члена кредитора либо бенефециария); (iii) перечисление платежей является вознаграждением за оказанные услуги.

\section{Свобода движения услуг}

Основы правового регулирования свободного движения услуг заложен в главе 3 раздела III Договора об учреждении Европейского Сообщества. По смыслу указанного договора в ст. 50 под услугами понимаются “те услуги, которые обычно предоставляются за вознаграждение, в той степени, в какой они не регулируются положениями, относящимися к свободному обращению товаров, капиталов и лиц» ${ }^{47}$. Право Европейского Союза классифицирует услуги на оказываемые физическими лицами и оказываемые юридическими лицами. Термин «услуги» включает (i) деятельность промышленного характера; (ii) деятельность коммерческого характера; (iii) деятельность в области ремесел и (iv) деятельность лиц свободных профессий ${ }^{48}$. Данное определение содержит экономический акцент понятия «услуги». По обоснованному замечанию С.Ю. Кашкина , «возмездный характер оказания услуг-основной и принципиальный критерий, отличающий услуги от благотворительности и выполнения официальных обязанностей» ${ }^{49}$.

Используя данную логику, Суд ЕС дал расширительное толкование экономическому содержанию понятия «услуги», указав, что «предоставление услуг должно быть реальным и эффективным, не малозначительным и не вспомогательным, поскольку они оказываются за вознаграждение» ${ }^{50}$.

\footnotetext{
47 Договор об учреждении Европейского Сообщества, 1992. Право Европейского Союза: Документы и комментарии. Под ред. проф. Кашкина С.Ю. М., ТЕРРА, 1999. С. 171.

${ }^{48}$ Там же.

49 Право Европейского Союза. Учебник для вузов. Под ред. С.Ю. Кашкина. 3-е изд., перераб. и доп. М., Юрайт, 2010. С. 499.

${ }^{50}$ Case C-51/96; Case C-191/97 Deliege v. Ligue Francophoende Judo and Disciplines Associees ASBL; Ligue Belge de Judo ASBL and others. (2000) ECR I-2549.
} 
Аналогичное содержание термина «услуги» содержит Директива об услугах на внутреннем рынке, определяя их следующим образом: «любая самостоятельная экономическая деятельность, обычно оказываемая за вознаграждение» (ст. 4)

Суд ЕС, осуществляя толкование ст. 49 Договора об учреждении Европейского Сообщества, признал, что в рамках норм этой статьи государства-члены должны отменить любые правила, дискриминирующие между иностранцами-гражданами ЕС, предоставляющими услуги на их территории, и своими гражданами, оказывающими аналогичные услуги. Дополнительно они обязаны устранить ограничения свободы предпринимательской деятельности и свободного предоставления услуг ${ }^{52}$. Аналогичной позиции Суд ЕС придерживался в деле Dona v. Montera ${ }^{53}$. Толкование норм ст. 49 Договора об учреждении Европейского Сообщества и практика Суда ЕС позволяет выделять ряд элементов, определяющих содержание свободы движения услуг, к которым относятся следующие: (i) передвижение лица на территории другого государства-члена с целью оказания услуг; (ii) передвижение лица на территории другого государства-члена с целью получения услуг; (iii) движение услуг без сопутствующего передвижения лиц. Последний элемент свободы движения услуг имеет наиболее применим к финансовой сфере, поскольку его реализация может осуществляться путем использования телекоммуникационных сетей. Специфика средств связи, с помощью которых оказываются услуги в финансовом секторе, создает для государств-членов множество поводов на введение ограничений на подобную деятельность.

Обращаясь к практике Суда ЕС, можно сделать вывод, что государства-члены могут устанавливать ограничения исключительно при наличии соответствующих положений в Договоре об учреждении Европейского Сообщества или в тексте решения по делу Casssis ${ }^{54}$. Что касается

\footnotetext{
${ }^{51}$ Directive 2006/123/EC of the European Parliament and of the Council of 12 December 2006 on services in the internal market. OJ L 376, 27.12.2006, p. 36-68.

${ }^{52}$ Case C-76/90, Sager v. Dennemeyer\&Co. Ltd., (1991) ECR I-4221.

${ }^{53}$ Case C-13/76, Dona v. Montera (1976) ECR I-1402.

${ }^{54}$ Case C-186/87, Cowan v. French Treasure, (1989) ECR 185.
}

сферы финансовых услуг, то показательным является дело Alpine Investments. В решении по данному делу Суд сделал вывод о правомерности установления ограничения оказания определенных финансовых услуг данной компанией, поскольку его целью является «защита деловой репутации финансового сектора» ${ }^{55}$.

С формальной точки зрения Договор об учреждении Европейского Сообщества не либерализует все виды услуг. В п. 2 ст. 51 данного Договора предусмотрено, что либерализации подлежат лишь две составляющих финансовых услуг - банковские и страховые услуги, имеющие связь с движением капиталов. Как справедливо указывает Кашкин С.Ю., условием такой либерализации является соответствующая либерализация движения капитала ${ }^{56}$.

Дальнейшее развитие и конкретизацию свобода движения услуг, установленная нормами главы 3 Римского договора, получила в нормах вторичного права, показательными источниками которых применительно к банковскому субсектору рынка финансовых услуг могут быть Директива 73/183 об отмене ограничений на право учреждения и право свободы предоставления услуг в отношении самостоятельной деятельности банков и других финансовых организаций ${ }^{57}$, Директива 89/646 ${ }^{58}$. Тем не менее, для либерализации конкретного вида услуг требовалось принятие отдельного законодательного акта в форме директивы, как это установлено в ст. 52 Договора об учреждении Европейского Сообщества. Применительно к сфере финансовых услуг первыми документами в этой сфере являются Директива 89/646 о свободе учреждения и свободе предоставления услуг

\footnotetext{
${ }^{55}$ Case C-34/95, C-35/95. C-35/96 Komsummentombudsmannen v. DeAgostini (Svenska) Forlag AB and Komsummentombudsmannen v. TV Shop Sverge AB, (1998) ER 687.

${ }^{56}$ Право Европейского Союза. Учебник для вузов. Под ред. С.Ю. Кашкина. М., Юристъ, 2002. С. 455.

${ }^{57}$ Council Directive 73/183/EEC of 28 June 1973 on the abolition of restrictions on freedom of establishment and freedom to provide services in respect of self- employed activities of banks and other financial institutions. OJ L 194, 16.7.1973, p. 1-10.

${ }^{58}$ Second Council Directive 89/646/EEC of 15 December 1989 on the coordination of laws, regulations and administrative provisions relating to the taking up and pursuit of the business of credit institutions and amending Directive 77/780/EEC. OJ L 386, 30.12.1989, p. 1-13.
} 
кредитными учреждениями и Директива 93/22 о инвестиционных услугах на рынке ценных бумаг.

В настоящее время свобода движения услуг регулируется нормами главы 3 раздела IV Договора о функционировании Европейского Союза и отдельными источниками вторичного права ЕС применительно к различным сферам услуг. Однако, нормы указанного Договора дублируют содержание соответствующих норм, установленных Договором об учреждении Европейского Сообщества. Примечательно, что для регулирования банковских и страховых услуг созданы специальные правовые режимы, исключающие указанные услуги из сферы действия общих положений относительно свободы движения услуг. К аналогичной категории относятся иные составляющие финансовых услуг (услуги на рынке ценных бумаг), что подтверждается их включением в список услуг Директивы 2006/123, на который не распространяется общий режим, и наличием целого массива специальных регулирующих актов.

Таким образом, анализируемые основные свободы, являющиеся основой действующего права Европейского Союза и отнесенные к совместной компетенции с государствами-членами, представляют собой «сердцевинный стержень европейской экономической интеграции» ${ }^{59}$, используемый для создания фундамента и укрепления механизма правового регулирования политики Союза в области финансовых услуг.

Вместе с тем необходимо отметить, что косвенное влияние на создание юридической конструкции, обеспечивающей слаженную работу механизма правового регулирования политики EC в области финансовых услуг, реализуемых в рамках однородного экономического пространства Союза, оказало создание Экономического и валютного союза (ЭВС), именуемый учеными «самой высокой ступенью экономической интеграции» ${ }^{60}$ и созданный в рамках практической реализации доклада Делора ${ }^{61}$. Положения о ЭВС закреплены в Договоре о Европейском Союзе.

\footnotetext{
${ }^{59}$ Бартенев С.А. Указ. соч. С. 141.

${ }^{60}$ Apax M. Европейский Союз. Видение политического объединения. М., 1998. С. 369.

${ }^{61}$ Международная экономическая интеграция. Учеб. пособие. Под ред. д-ра экон. наук, проф. Н.Н. Ливенцева. - М.: Экономистъ, 2006. С. 137.
}

Особенность такого влияния заключается в наличии у ЭВС специальной функциональной нагрузки, результатом чего стало завершение программы формирования единого внутреннего рынка, принципы которого легли в основу интегрирования рынка финансовых услуг в EC. В наибольшей степени влияние ЭВС на регулирование рынка финансовых услуг проявляется сквозь призму следующих параметров: свободное осуществление платежей в евро, являющимся «единственным законным платежным средством на всей территории валютного союза» ${ }^{62}$; либерализация движения капитала внутри $\mathrm{EC}$; координация макроэкономической политики государств-членов $\mathrm{EC}^{63}$; взаимодействие Европейского центрального банка, одной из важнейших функций которого является способствование в осуществлении пруденциального банковского надзора за кредитными организациями, и национальных центральных банков, позволяющее по убеждению Д. Серве, сформировать «системное объединение финансовых рынков государств-членов в рамках единого экономического пространства Союза» ${ }^{64}$.

На основании вышеизложенного можно сделать следующий вывод. В ходе интеграции финансовых рынков государств-членов ЕС и реализации Союзом политики в области финансовых услуг правовым базисом указанных процессов служат свободы движения капитала, платежей и услуг, нашедшие отражение в учредительных документах Союза, являющихся источниками первичного права. Дальнейшая либерализация указанных свобод получила закрепление в источниках вторичного права, а также правоприменительной практике Суда ЕС. Такая юридическая конструкция не случайна, поскольку как указывает С.А. Трыканова, «правовым инструментом реализации политики ЕС является право Сообщества» ${ }^{65}$.

\footnotetext{
${ }^{62}$ Европейское право. Право Европейского Союза и правовое обеспечение защиты прав человека. Учебник. Рук. авт. колл. и отв. ред. Л.М. Энтин. 3-е изд., пересмотр. и доп. - М.: Норма: ИНФРА-М, 2001. С. 710.

${ }^{63}$ Каблова Л.В. Указ. соч. С. 60.

${ }^{64}$ Servais, D. A Single Financial Market. Brussels. 1995. p. 89.

${ }^{65}$ Актуальные проблемы европейского права. М.: Флинта, МПСИ, 2008. С. 21.
} 
Дополнительным элементом, усилившим правовой базис политики ЕС в области финансовых услуг, выступает Экономический и валютный союз, способствующий применению принципов свободной рыночной экономики со свободной конкуренцией, которыми должны руководствоваться институты ЕС при реализации экономической политики, в рамках которой происходит интегрирование рынка финансовых услуг.

\section{Библиография:}

1. Дубовицкая Е.А. Европейское корпоративное право. 2-е изд., перераб. и доп. М., Волтерс Клувер, 2008.

2. Право Европейского Союза в вопросах и ответах. Учебное пособие. Под ред. Кашкина С.Ю. М., Проспект, 2008.

3. Международные экономические отношения. Учебник для вузов. Под. ред. проф. В.Е. Рыбалкина. 5-е изд., перераб. и доп. М., ЮНИТИ-ДАНА, 2005.

4. Договор об учреждении Европейского Сообщества, 1992.

5. Право Европейского Союза: Документы и комментарии. Под ред. проф. Кашкина С.Ю. М., TЕРPA, 1999.

6. Право Европейского Союза: правовое регулирование торгового оборота. Учебное пособие. Под ред. проф. В.В. Безбаха, доц. А.Я. Капустина, проф. В.К. Пучинского. - М., ЗЕРЦАЛО, 2000.

7. Ковалев А.А. Международное право и правовое регулирование международной экономической деятельности. Учебное пособие. М., Научная книга, 2007.

8. Бартенев С.А. Европейский Союз и государства-члены: разграничение компетенции. М., Юрлитинформ, 2009.

9. Право Европейского Союза. Учебник для вузов. Под ред. С.Ю. Кашкина. 3-е изд., перераб. и доп. М., Юрайт, 2010.

10. Право Европейского Союза. Учебник для вузов. Под ред. С.Ю. Кашкина. М., Юристъ, 2002.

11. Арах М. Европейский Союз. Видение политического объединения. М., 1998.

12. Международная экономическая интеграция. Учеб. пособие. Под ред. д-ра экон. наук, проф. Н.Н. Ливенцева. - М.: Экономисть, 2006.

13. Европейское право. Право Европейского Союза и правовое обеспечение защиты прав человека. Учебник. Рук. авт. колл. и отв. ред. Л.М. Энтин. 3-е изд., пересмотр. и доп. - М.: Норма: ИНФРА-М, 2001. , Т.

14. The Free Movement of Capital in the European Union. The Regulation of International Financial Markets: Perspectives for Reform. - Cambridge University Press, 2006.

\section{References (transliteration):}

1. Dubovickaja E.A. Evropejskoe korporativnoe pravo. 2-e izd., pererab. i dop. M., Volters Kluver, 2008.

2. Pravo Evropejskogo Sojuza v voprosah i otvetah. Uchebnoe posobie. Pod red. Kashkina S.Ju. M., Prospekt, 2008.

3. Mezhdunarodnye jekonomicheskie otnoshenija. Uchebnik dlja vuzov. Pod. red. prof. V.E. Rybalkina. 5-e izd., pererab. i dop. M., JuNITI-DANA, 2005.

4. Pravo Evropejskogo Sojuza: Dokumenty i kommentarii. Pod red. prof. Kashkina S.Ju. M., TERRA, 1999.

5. Pravo Evropejskogo Sojuza: pravovoe regulirovanie torgovogo oborota. Uchebnoe posobie. Pod red. prof. V.V. Bezbaha, doc. A.Ja. Kapustina, prof. V.K. Puchinskogo. - M., ZERCALO, 2000. 
6. Kovalev A.A. Mezhdunarodnoe pravo i pravovoe regulirovanie mezhdunarodnoj jekonomicheskoj dejatel'nosti. Uchebnoe posobie. M., Nauchnaja kniga, 2007.

7. Bartenev S.A. Evropejskij Sojuz i gosudarstva-chleny: razgranichenie kompetencii. M., Jurlitinform, 2009.

8. Pravo Evropejskogo Sojuza. Uchebnik dlja vuzov. Pod red. S.Ju. Kashkina. 3-e izd., pererab. i dop. M., Jurajt, 2010.

9. Pravo Evropejskogo Sojuza. Uchebnik dlja vuzov. Pod red. S.Ju. Kashkina. M., Jurist\#, 2002.

10. Arah M. Evropejskij Sojuz. Videnie politicheskogo ob\#edinenija. M., 1998.

11. Mezhdunarodnaja jekonomicheskaja integracija. Ucheb. posobie. Pod red. d-ra jekon. nauk, prof. N.N. Livenceva. - M.: Jekonomist\#, 2006.

12. Evropejskoe pravo. Pravo Evropejskogo Sojuza i pravovoe obespechenie zashhity prav cheloveka. Uchebnik. Ruk. avt. koll. i otv. red. L.M. Jentin. 3-e izd., peresmotr. i dop. - M.: Norma: INFRA-M, 2001. , T. 